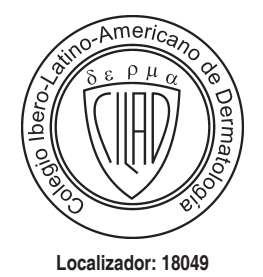

doi: $10.35366 / 91764$
Palabras clave: Exantema, infancia, enfermedad rara.

Keywords: Exanthem, chilhood, rare disease.
* Médico tratante Especialista en Dermatología, Máster en Tricología y Trasplante capilar, Hospital Alfredo Noboa Montenegro, Guaranda-Ecuador. ${ }^{\ddagger}$ Médico especialista en Dermatología, Tutora del Postgrado de Dermatología del ISP Universidad Central, Quito-Ecuador.

\$ Médico tratante especialista en pediatría. Hospital Baca Ortiz, Quito-Ecuador.

Hospital Dermatológico Gonzalo-González. Universidad Central del Ecuador.

Conflicto de intereses: Ninguno.

Recibido: 16/Julio/2018. Aceptado: 24/Febrero/2019.

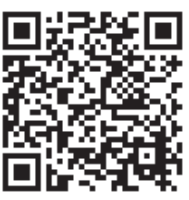

\section{REsuMEN}

El exantema periflexural asimétrico de la infancia es una patología infrecuente, poco conocida y escasamente descrita; a pesar de que fue definida hace más de cinco décadas, existen escasos reportes e investigaciones sobre el tema, motivo por el cual aún se desconoce su etiopatogenia con exactitud, y su diagnóstico resulta desafiante. Sin embargo, la clínica característica de la enfermedad, su evolución y su propiedad autolimitada permite reconocerla. Presentamos un reporte de caso en una niña de 1 año y 6 meses de edad y su evolución semanal hasta su autolimitación.

\author{
Medicina Cutánea \\ Ibero-Latino-Americana \\ https://dx.doi.org/10.35366/91764
}

\title{
Exantema periflexural asimétrico de la infancia: evolución de un caso clínico
}

\author{
Asymmetric periflexural exanthem of childhood: evolution of a clinical case
}

Margarita Torres-Cruz, ${ }^{*}$ Marlene Legna-Zambrano, ${ }^{\ddagger}$ Diana Janeth Legña-Tibanta ${ }^{\S}$

\section{ABSTRACT}

The Asymmetric periflexural exanthem of childhood is an infrequent pathology, unknown and scarcely described; although it was defined more than five decades ago, there are few reports and research on the subject, which is why its ethiopathogenesis is still unknown, and its diagnosis is challenging. However, the clinical characteristic of the disease, its evolution and its selflimited property allows it to be recognized. We present a case report in a girl of 1 year and 6 months of age and her weekly evolution until her self-limitation.

\section{INTRODUCCIÓN}

E exantema periflexural asimétrico de la infancia es un síndrome clínico sin un factor desencadenante o precipitante obvio, está caracterizado por la aparición aguda de una erupción unilateral maculopapular, escarlatiniforme o eccematosa que inicia en las axilas y/o las ingles y se extiende hacia el tronco y las extremidades. La erupción puede ser pruriginosa, y a menudo se expande de forma centrífuga hasta llegar a ser bilateral al final del curso de la enfermedad. ${ }^{1}$ La causa por la que la afección prefiere una localización anatómica asimétrica y unilateral es inexplicable, lo que le confiere un cuadro clínico muy característico.

El término exantema periflexural asimétrico de la infancia (APEC) fue acuñado por Taeib y colaboradores, ${ }^{2}$ para representar exantemas similares que fueron descritos inicialmente bajo los epígrafes de «nuevo exantema papular de la niñez» y «exantema laterotorácico unilateral de los niños». Desde su descripción en 1959, se han reportado en la literatura alrededor de 300 casos. La poca frecuencia con la que se co- munica esta patología se ha relacionado con el escaso conocimiento acerca de la enfermedad. ${ }^{3}$

\section{PRESENTACIÓN DEL CASO}

Paciente femenino de un año y seis meses de edad con antecedente de displasia de cadera congénita resuelta quirúrgicamente, presenta hace tres semanas y sin causa aparente algunas lesiones en región axilar y pectoral derecha que se irradia al hemitorax derecho, acompañado de prurito y malestar general.

Al examen físico, se evidencia una dermatosis en hemitorax superior derecho que abarca región escapular, cara lateral torácica y región pectoral constituida por una erupción monomorfa unilateral conformada por múltiples pápulas de 2 a $3 \mathrm{~mm}$, que confluyen en placas eritematosas de bordes difusos y disposición lineal, escasas placas anulares en tórax anterior, y algunas pápulas y placas eritematosas aisladas en abdomen y extremidad superior derecha (Figura 1), sin adenopatías cervicales o inguinales, ni toma del estado general del paciente.

Se realizó estudio histopatológico que reporta una acantosis epidérmica leve con 
ocasionales células disqueratósicas y grupos de células de Langerhans, en la dermis presenta infiltrado perivascular y de interface que exocita a la epidermis, rodea las glándulas ecrinas e infiltra el epitelio infundibular (Figura 2), datos compatibles con un exantema unilateral latero torácico.

Se inició tratamiento sintomático con emolientes y observación semanal, a la cuarta semana se evidencia disminución del eritema y mayor descamación (Figura 3), a la quinta semana las lesiones habían desaparecido completamente prevaleciendo xerosis en el sitio afectado, (Figura 4) y sin cambios cutáneos residuales. La evolución de la enfermedad, benigna y autolimitada se correlaciona con los reportes de la literatura.

\section{DISCUSIÓN}

El exantema unilateral torácico fue descrito inicialmente por Laur en $1962,{ }^{4}$ en ese mismo año, Brunner ${ }^{5}$ y colaboradores la definen como «nuevo eritema papular de la infancia». En 1967, Hjorth y su equipo ${ }^{6}$ describen una enfermedad con características similares bajo el nombre de «síndrome Gianotti-Crosti - erupción papular de la infancia». Luego en 1992, Bodemer y de Prost $^{7}$ describen 18 casos y la denominan exantema laterotorácico unilateral de la infancia, basados en la localización común de aparición y sugirieron su probable causa viral, mientras que Taieb y su grupo ${ }^{8}$ en 1993, al observar que no siempre afecta de forma unilateral y que podía incluso involucrar a las extremidades inferiores, sugirieron utilizar el término exantema periflexural asimétrico de la infancia (APEC) 9,10

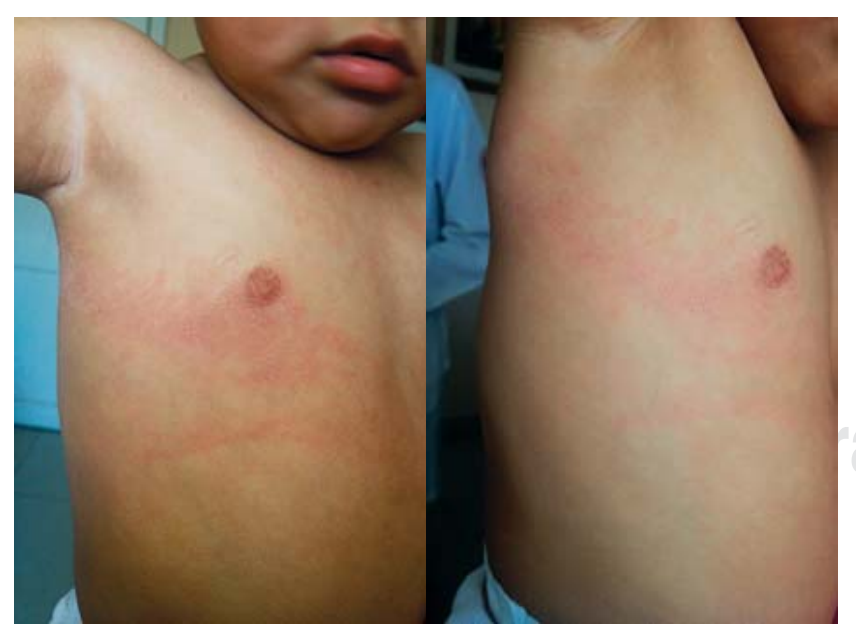

Figura 1: Erupción papular eritematosa lineal y anular dispersa en hemitórax derecho y tórax anterior a las 3 semanas de evolución.

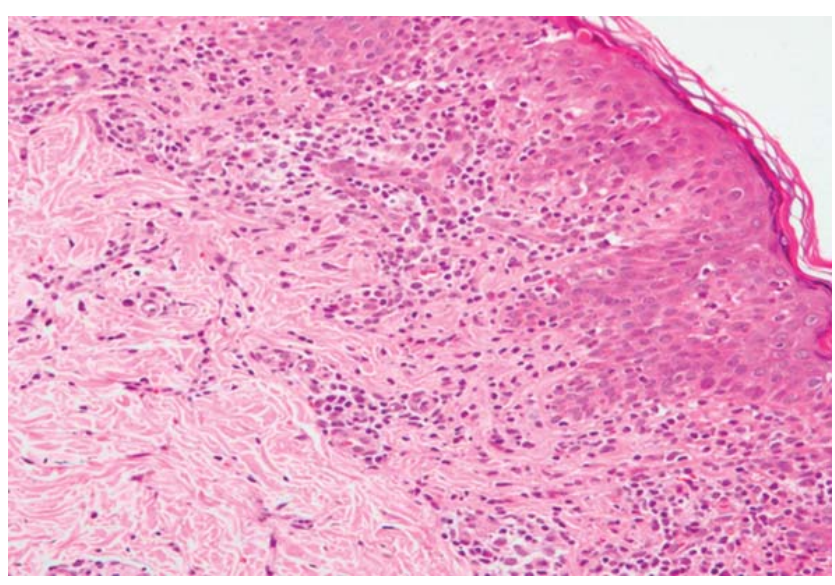

Figura 2: Acantosis con células disqueratósicas ocasionales y células de Langerhans; en dermis superior infiltrado perivascular y de interface que exocita hacia epidermis, rodea las glándulas ecrinas e infiltra el epitelio infundibular.

Se han reportado aproximadamente 300 casos en la literatura, sin embargo, la mayoría de los autores coinciden en que la falta de diagnóstico se relaciona con el desconocimiento de la enfermedad. ${ }^{11}$

Se presenta en lactantes y preescolares de entre uno y cuatro años de edad, observándose con mayor frecuencia en mujeres con relación 2:1, y predominio en infantes con piel clara. Se observa en cualquier época del año, con predominio en primavera e invierno. Se han reportado pocos casos en adultos ${ }^{12} y$ de forma excepcional en el embarazo. ${ }^{13}$

El cuadro típico inicia con un niño sano, usualmente precedido por un pródromo de síntomas respiratorios superiores o digestivos; pueden existir adenopatías y alza térmica leve a moderada, posterior a lo que presenta súbitamente un exantema de pápulas monomorfas aplanadas eritematosas de 1-3 mm de diámetro, de aspecto morbiliforme, escarlatiniforme o eccematoide. Se han descrito patrones reticulares, anulares, con escoriaciones, vesículas, lesiones purpúricas aisladas o confluentes en placas.

Inicia en una axila o en la cara lateral del hemitórax, posteriormente se extiende en forma centrífuga al brazo ipsilateral, flanco y muslo. Puede comprometer el lado contrario después de ocho o 15 días, aunque siempre afecta más a las primeras regiones. La erupción tiene la particularidad de respetar la cara, manos y pies. ${ }^{3}$ En muy raras ocasiones se generaliza.

En la primera semana de la enfermedad, la erupción se disemina centrífugamente desde el tórax, y puede volverse bilateral o generalizada. A pesar de la diseminación, las pápulas continúan asimétricas, con mayor compromiso 
de la región originariamente afectada. Pasada la primera semana, las lesiones pueden parecer más escarlatiniformes, morbiliformes o eczematosas. Hacia la tercera semana las lesiones rosadas se resuelven, dejando solamente piel seca residual. La erupción resuelve espontáneamente entre las tres y seis semanas sin dejar secuelas. ${ }^{14}$

Mejía Rodríguez y colaboradores ${ }^{11}$ clasifican clínicamente el curso de las lesiones en cuatro fases:

1. Eccematosa: lesiones iniciales en axila y cara lateral del tórax.

2. Coalescente: cuando se extienden a tronco y extremidades proximales, separadas por áreas de piel de aspecto normal.

3. Regresión: las lesiones iniciales desarrollan un centro gris hiperpigmentado.

4. Descamativa: presencia de escama fina residual que se resuelve con el tiempo.

La mayoría de los niños se presentan asintomáticos, aunque en la mitad de los casos se observa prurito leve a moderado. Puede presentarse con linfadenopatía localizada en el área de inicio del exantema.

Se ha sugerido que la APEC, por su relación temporal en $75 \%$ de los casos con pródromos como rinitis, fiebre y diarrea, podría estar relacionada con una causa viral; ${ }^{15}$ los virus que han sido implicados son la parainfluenza 2 y 3 , el adenovirus, parvovirus B19, ${ }^{16}$ citomegalovirus, virus del Ebstein Barr ${ }^{17}$ y existen casos reportados de Herpes Virus $7 .{ }^{18} \mathrm{Sin}$ embargo, el origen de esta erupción sigue

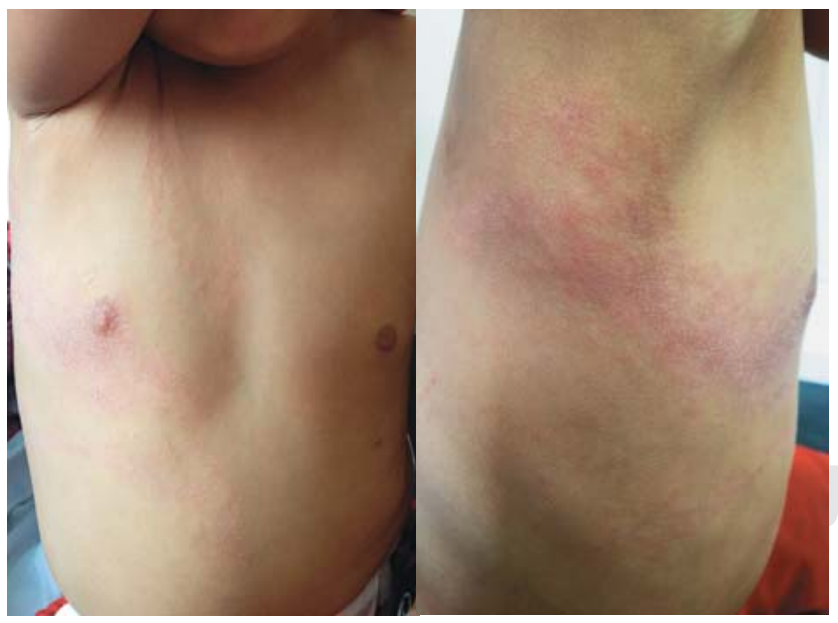

Figura 3: A las cuatro semanas de evolución: lesiones acentuadas, se evidencia el compromiso de región abdominal y torax anterior derecho respetando el lado contraleteral.

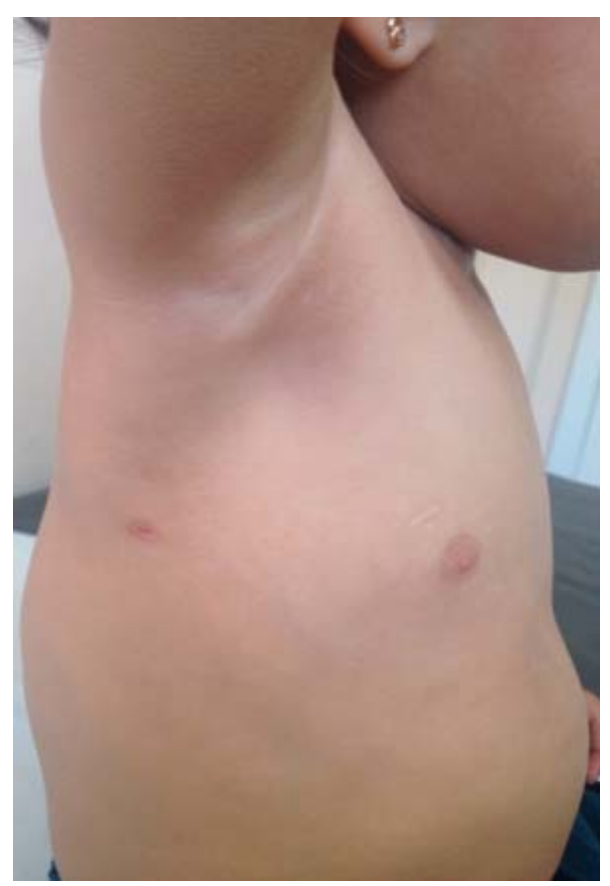

Figura 4: A las cinco semanas de evolución: ausencia de lesiones.

siendo desconocida a pesar de la búsqueda activa de una causa infecciosa. ${ }^{19,20}$ Una mutación postcigótica en una etapa temprana de la embriogénesis que hace que los queratinocitos de un lado del cuerpo sean más reactivos a los agentes infecciosos, podría explicar el predominio unilateral de la erupción. ${ }^{21}$

El diagnóstico es básicamente clínico, ya que hasta la fecha no hay técnicas diagnósticas específicas que corroboren la enfermedad. En los exámenes de laboratorio presenta una ligera elevación de la velocidad de sedimentación globular. ${ }^{11}$

El estudio histopatológico es poco usado e inespecífico considerando el carácter autolimitado de la entidad, se observa una dermatitis de interfaz mononuclear leve a moderada, con algunos queratinocitos necróticos y apoptóticos, y un infiltrado dérmico mononuclear predominando linfocitos $T$ con predominio de células $T$ CD4+, mezclado con escasos linfocitos B. El infiltrado es esencialmente dérmico, con un claro predominio alrededor de las glándulas sudoríparas desde el acrosiringio hasta la glándula sudorípara en espiral, con una afectación menos pronunciada alrededor de los vasos sanguíneos y los folículos pilosos. ${ }^{22}$

No existe un tratamiento específico y el manejo básicamente es sintomático, con antihistamínicos y emolientes. 
Los esteroides de baja potencia proporcionan una mínima o nula respuesta, por lo que no se justifica su uso. ${ }^{19}$

\section{CONCLUSIONES}

La importancia del reconocimiento temprano de este exantema, es impedir la exhaustiva labor de investigación y el uso de recursos de uso rutinario para establecer un diagnóstico en erupciones atípicas; asimismo, una definición precisa de la enfermedad permite disminuir la ansiedad del paciente y sus familiares.

\author{
Correspondencia: \\ Margarita Torres-Cruz \\ Av. Ricardo Descalzi y Calle Q N73-52 Urbanización \\ El Condado, Quito-Ecuador. \\ Tel: +59302249 1662, +593960110968 \\ E-mail: magytc1405@gmail.com
}

\title{
BIBLIOGRAFÍA
}

1. Zawar VP. Asymmetric periflexural exanthema: a report in an adult patient. Indian J Dermatol Venereol Leprol. 2003; 69: 401-404

2. Taïeb A, Megraud F, Legrain V, Mortureux P, Maleville J. Asymmetric periflexural exanthem of childhood. J Am Acad Dermatol. 1993; 29: 391-393.

3. Robles G, Cuevas-Suárez del Real B, Pérez-Soto B, TrujilloLinares P, Zamudio-Vega P. Exantema unilateral latero-torácico: ¿una nueva enfermedad? Rev Mex Pediatr. 2007; 74 (6): 266226.

4. Laur WE. Unilateral laterothoracic exanthema in children. J Am Acad Dermatol. 1993; 29: 799.

5. Brunner MJ, Rubin L, Dunlop F. A new papular erytema of childhood. Arch Dermatol. 1962; 85: 539-540.

6. Hjorth N, Kopp H, Osmundsen PE. Gianotti-Crosti syndrome: papular eruption of infancy. Trans St John's Hosp Dermatol Soc. 1967; 53: 46-56

7. Bodemer $\mathrm{C}$, de Prost $\mathrm{Y}$. Unilateral laterothoracic exanthem in children: a new disease? J Am Acad Dermatol. 1992; 27 (5 Pt 1): 693-696.

8. Taïeb A, Mégraud F, Legrain V, Mortureux P, Maleville J. Asymmetric periflexural exanthem of childhood. J Am Acad Dermatol. 1993; 29 (3): 391-393.

9. Galán GM, Moreno GJC. Exantemas virales en la infancia. Pediatr Integral. 2004; 8 (4): 289-314.

10. Mejía-Rodríguez SA, Ramírez-Romero VS, Valencia-Herrera A, Mena-Cedillos C. Exantema laterotorácico unilateral de la infancia, una enfermedad poco diagnosticada. Bol Med Hosp Infant Mex. 2007; 64 (1): 65-68.

11. Gutzmer R, Herbst RA, Kichl P, Kapp A, Weiss J. Unilateral laterothoracic exanthema (asymmetrical periflexural exanthema of childhood); report of an adult patient. J Am Acad Dermatol. 1997; 37: 484-485.
12. Robin-Carder K, Weston W L. Exantemas virales atípicos: nuevos exantemas y variaciones de algunos otros. Correo SAP. Departamento de Dermatología, University of Colorado Health Sciences Center, Denver, EUA.

13. Chiriac A, Chiriac A, Foia L.Unilateral laterothoracic exanthem in a pregnant woman - case report. Our Dermatol Online. 2012; 3 (4): 332-333.

14. Al Yousef A, Farhi D, De Maricourt S, Dupin N. Asymmetric periflexural exanthema associated with HHV7 infection. Eur J Dermatol. 2010; 20 (2): 230-231. doi: 10.1684/ejd.2010.0854.

15. Gragasin FS, Metelitsa AI. Unilateral laterothoracic exanthem. CMAJ. 2012; 184 (3).

16. Pauluzzi P, Festini G, Gelmetti C. Asymmetric periflexural exanthem of childhood in an adult patient with parvovirus B19. J Eur Acad Dermatol Venereol. 2001; 15: 372-374.

17. Scheinfeld N. Unilateral laterothoracic exanthema with coincident evidence of Epstein Barr virus reactivation: exploration of a possible link. Dermatol Online J. 2007; 13: 13.

18. Morales ME, Ríos H, Méndez Y. Exantema unilateral. Rev Cent Dermatol Pascua. 2012; 21: 3.

19. Harangi F,Varszegi D,Szues G. Asymmetric periflexural exanthem of childhood and viral examinations. Pediatr Dermatol. 1995; 12: 112-115.

20. McCuaig C, Russo P, Powell J, Label P, Marcoux D. Unilateral laterothoracic exanthem: a clinicopathologic study of forty-eight patients. J Am Acad Dermatol. 1996; 34: 979-984.

21. Niedermeier A, Pfutzner W, Ruzicka T, Thomas P, Happle R. Superimposed lateralized exanthem of childhood: report of a case related to adenovirus infection. Clin Exp Dermatol. 2014; 39: 351-353.

22. Coustou D, Léauté-Labrèze $C$, Bioulac-Sage P, Labbe L, Taïeb A. Asymmetric periflexural exanthem of childhood a clinical, pathologic, and epidemiologic prospective study. Arch Dermatol. 1999; 135: 799-803. 